\title{
Post-bleaching coral community change on southern Maldivian reefs: is there potential for rapid recovery?
}

\author{
C. T. Perry ${ }^{1}$ (D) K. M. Morgan ${ }^{1}$
}

Received: 20 June 2017/ Accepted: 20 July 2017 / Published online: 28 July 2017

(c) The Author(s) 2017. This article is an open access publication

\begin{abstract}
Given the severity of the 2016 global bleaching event, there are major questions about how quickly reef communities will recover. Here, we explore the ecological and physical structural changes that occurred across five atoll interior reefs in the southern Maldives using data collected at 6 and 12 months post-bleaching. Following initial severe coral mortality, further minor coral mortality had occurred by 12 months post-bleaching, and coral cover is now low $(<6 \%)$. In contrast, reef rugosity has continued to decline over time, and our observations suggest transitions to rubble-dominated states will occur in the near future. Juvenile coral densities in shallow fore-reef habitats are also exceptionally low ( $<6$ individuals $\mathrm{m}^{-2}$ ), well below those measured 9-12 months following the 1998 bleaching event, and below recovery thresholds identified on other Indian Ocean reefs. Our findings suggest that the physical structure of these reefs will need to decline further before effective recruitment and recovery can begin.
\end{abstract}

Keywords Coral bleaching · Maldives - Coral cover . Rugosity $\cdot$ Coral recruitment $\cdot$ Juvenile corals

Topic Editor Morgan S. Pratchett

C. T. Perry

c.perry@exeter.ac.uk

1 Department of Geography, College of Life and Environmental Sciences, University of Exeter, Exeter EX4 4RJ, UK

\section{Introduction}

Bleaching-induced coral mortality following sea-surface temperature (SST) warming events is considered the most pressing climate-related threat to coral communities (Hughes et al. 2017). Coral bleaching can drive large-scale mortality on even well-managed and geographically isolated reefs (Perry and Morgan 2017), and particularly affects those species/genera that typically dominate shallow reef habitats (e.g. Acroporids) (Baker et al. 2008; Pratchett et al. 2013). The 2016 bleaching event, which severely impacted coral communities across the IndoPacific (e.g. Hughes et al. 2017), including in the Maldives (Perry and Morgan 2017), will thus impact on the multiple ecosystem services that reefs provide in affected areas. Severe bleaching events have impacted the Maldives in the recent past, most notably during 1998 when coral mortality occurred at a comparable scale to that reported during 2016. Recovery post-1998 occurred within about 10-12 yr (Pisapia et al. 2016), a trend replicated at other remote Indian Ocean sites (e.g. Chagos; Sheppard et al. 2008). In other areas of the Indian Ocean, recovery trajectories post1998 were more divergent, with some reefs recovering successfully and others undergoing phase shifts to states with lower coral cover and diminished carbonate budgets (Graham et al. 2015). These studies thus collectively provide a basis for some optimism for recovery potential over decadal timescales.

However, recent modelling suggests that the frequency and intensity of bleaching events will increase over the next few decades (van Hooidonk et al. 2016), and that when considered in the context of increasing background SSTs, the likelihood for more globally widespread and intense bleaching events is high. This point is emphasised most clearly in recent work from Australia's Great Barrier 
Reef (GBR) which clearly shows the potential for different bleaching events with different spatial footprints, but with close temporal frequency, to collectively impact entire reef-building regions over short timescales (Hughes et al. 2017). A key implication is that the recovery landscapes for many contemporary reefs may become very different. Thus, there is a pressing need to understand the nature of coral community change post-contemporary bleaching, and to assess how, and in what way, coral communities will restructure. Here, we report on initial reef community transitions at five shallow atoll interior reef sites in the southern Maldives (Fig. 1a, b). These reefs were severely impacted by the ENSO-induced warming that affected the central Indian Ocean in mid2016 (Fig. 1c), with coral cover on shallow ( $<5 \mathrm{~m}$ depth) reefs declining from an average of $25.6 \pm 5.8$ to $6.3 \pm 1.9 \%$ (as measured for the true 3-dimensional reef surface), and the carbonate budgets of the reefs collapsing (Perry and Morgan 2017). Specifically, we assess initial changes in coral community composition and reef structural complexity using data collected in January 2016 (just prior to bleaching onset), and then from repeat surveys in September 2016 and March 2017, i.e. 6 and 12 months post-bleaching. We also present data on changes in parrotfish biomass and post-bleaching (March 2017) juvenile coral species abundance. These data collectively document a process of ongoing ecological and structural transition post the initial bleaching impacts, and suggests further declines are likely before reef recovery begins.
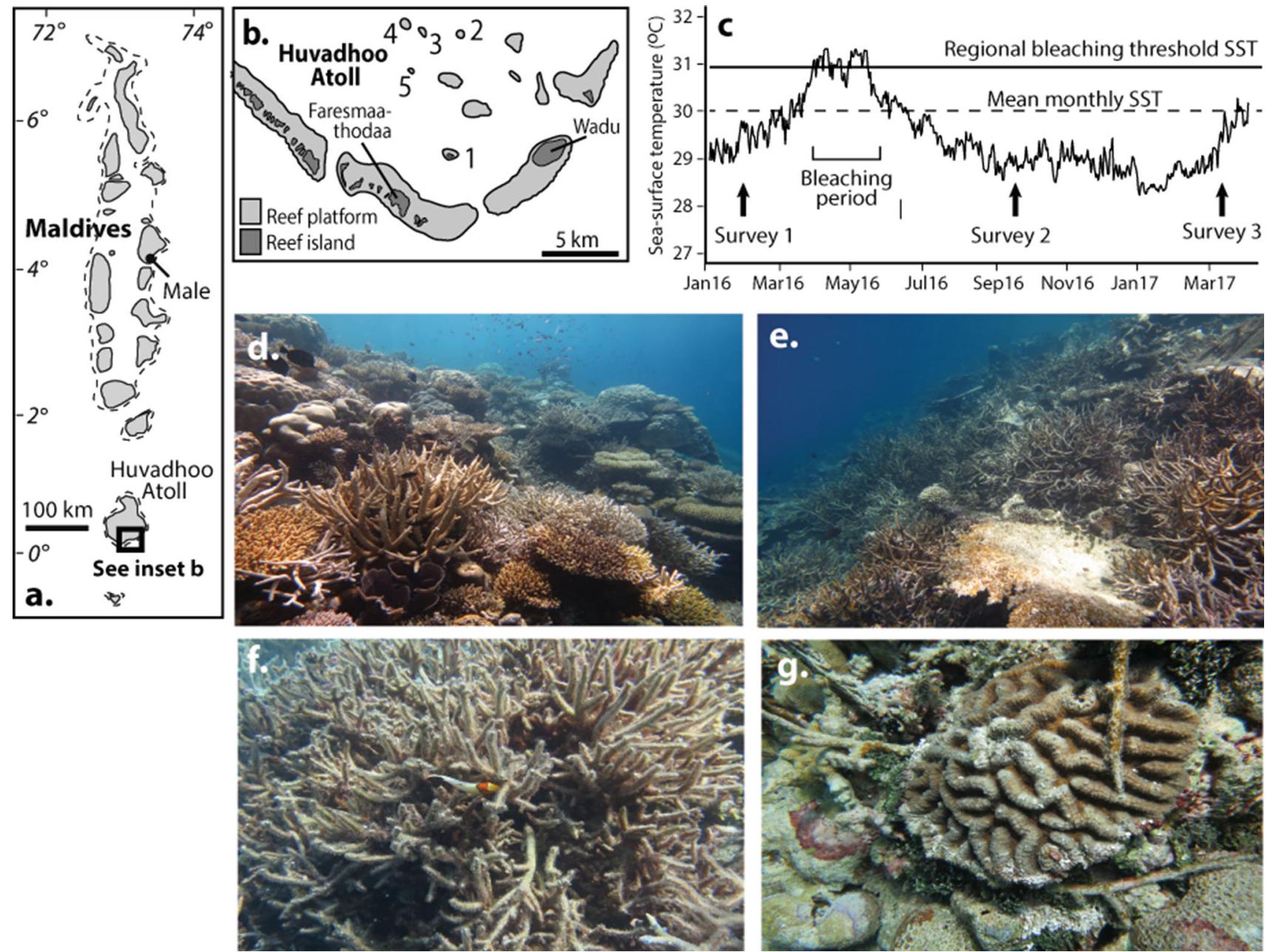

Fig. 1 a Regional setting of Huvadhoo Atoll, Maldives; b location of study sites-(1) Kandahalagala, (2) Mahutigala, (3) Kafigahlaa, (4) Kodehutigalaa, (5) Kadumaigala; c satellite-derived sea-surface temperature data for the Maldives (1/01/16 to 1/04/17). Data extracted from the NOAA Coral Reef Watch site (http://coralreefwatch.noaa. gov/vs/gauges/maldives.php), accessed 20/04/17; Images d to g show reef community states over time at Kandahalagala-d January 2016 - thriving Acropora spp. reefs, e September 2016-recently dead in situ framework, f March 2017-dead and turf/filamentous algal covered framework, $\mathbf{g}$ colony showing partial tissue mortality in March 2017 


\section{Study area and methods}

Surveys were conducted during January and September 2016, and March 2017 on five uninhabited atoll interior reefs in Huvadhoo atoll, southern Maldives (Fig. 1a, b). These reefs are minimally influenced by local disturbances, i.e. fishing pressure is low, and immediate point sources of nutrient input absent. Satellite SST data indicates that strong warming started in late March 2016 and persisted at levels above regional bleaching thresholds $\left(\sim 30.9{ }^{\circ} \mathrm{C}\right)$ until mid-May 2016 (Fig. 1c; NOAA 2016). Surveys were conducted along the fore-reef slope $2 \mathrm{~m}$ depth contour on the south-western margins of each reef $(n=5 \times 10 \mathrm{~m}$ transects per site). Substrate composition and rugosity were quantified using the ReefBudget methodology, as described in Perry and Morgan (2017), with coral cover and species abundance data calculated as a function of the 3-dimensional reef surface. Biomass of parrotfish was determined based on the collection of species-size-life phase data based on eight $30 \mathrm{~m} \times 4 \mathrm{~m}$ belt transects, with all surveys completed by the same experienced observer (K.M.M.). Biomass was calculated using length data and lengthweight relationships and multiplied by fish abundance. Juvenile coral data were collected at each site in March 2017, with data on genera and size (defined as corals up to $50 \mathrm{~mm}$ in maximum diameter, following Doropoulos et al. 2015) collected from 60 replicate $1-\mathrm{m}^{2}$ quadrats (10 per $10 \mathrm{~m}$ transect) at each site.

\section{Results and discussion}

Initial post-bleaching assessments during September 2016 showed that rapid and consistent declines in coral cover and reef carbonate budget states occurred across all sites (Fig. 1d, e; Perry and Morgan 2017). A re-survey of these same sites in March 2017 indicates that whilst mean coral cover had declined slightly in the intervening 6 months (Sept 2016: $6.3 \pm 1.9 \%$; March 2017: $5.9 \pm 2.3 \%$ ), these changes were not significant (Fig. 2a; $p>0.05$ ). This is attributed to the fact that the most abundant corals (Acropora spp.) had already died following bleaching, and thus a phase defined by a relatively more stable, but low coral cover, state has been reached. However, an additional observation from March 2017 was that many sub-massive and compact branched (e.g. Pocillopora spp.) taxa that had initially survived showed evidence of recent partial or complete mortality (Fig. 1g). The causes of this delayed mortality are unclear but much of the standing dead Acropora is covered with turf and fine filamentous algae (Fig. 1f), and we speculate that this may be creating localised micro-environments that act as vectors for disease (e.g. Barott et al. 2012).
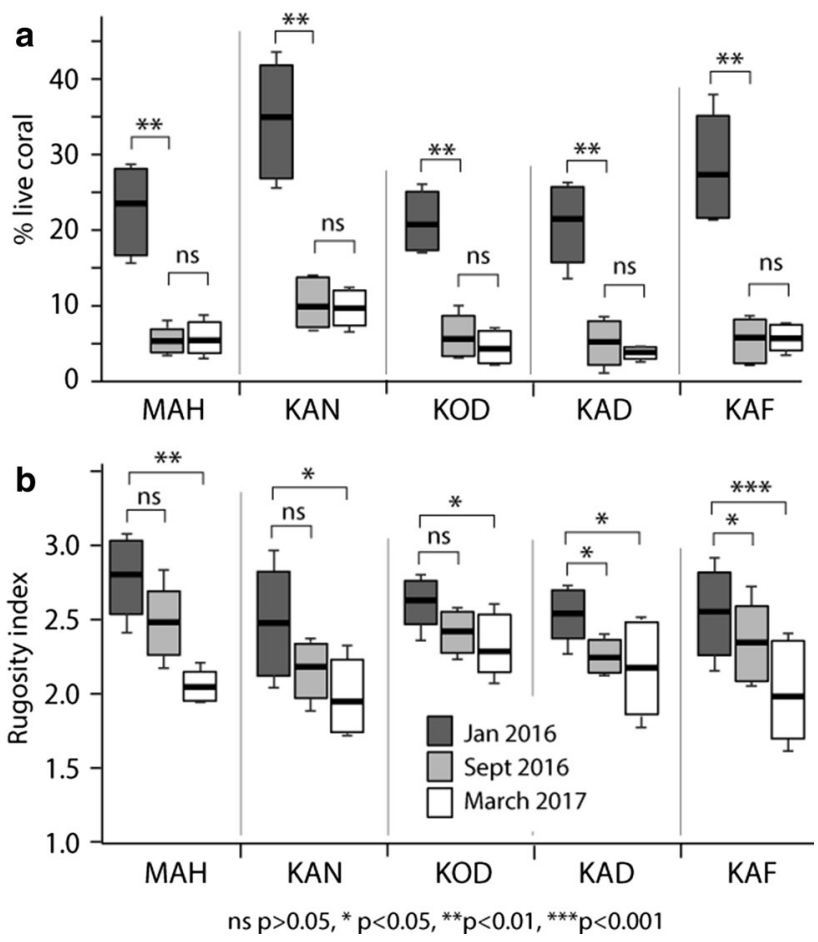

Fig. 2 Box (median and 50\% quartile) and whisker (95\% quantile) plots showing differences in a coral cover, and $\mathbf{b}$ rugosity between Jan 2016, Sept 2016 and March 2017. MAH-Mahutigala, KANKandahalagala, KOD—Kodehutigalaa, KAD—Kadumaigala, KAFKafigahlaa

Whilst coral cover changed little between September 2016 and March 2017, more significant changes in rugosity are now apparent. Rugosity did not decline significantly at most sites immediately post-bleaching (Fig. 2b). However, by March 2017 most sites have undergone significant declines compared to January 2016 (Jan 2016 mean: $2.6 \pm 0.1$; March 2017 mean: $2.1 \pm 0.2$; Fig. 2b). Whilst the branching structure of the dead Acropora spp. remained as of March 2017, the process of dead coral collapse is now underway. This has not yet reached what Lasagna et al. (2010) described as a "regressive" post-mortality stage on Maldivian reefs, i.e. where the substrates become coral rubble dominated, but this process of breakdown and conversion to rubble is in progress and is predicted to proceed rapidly following monsoonal transitions as increased wave conditions impact different reef aspects.

Accompanying these coral cover and rugosity declines have been major changes in the relative abundance of both individual coral genera and parrotfish. Significant declines in the relative abundance of previously dominant Acropora spp. (Fig. 3a) occurred at all sites (Jan 2016: $56.7 \pm 7.1 \%$; Sept 2016: $19.6 \pm 7.9 \% ; p<0.001)$, and their abundance has further declined slightly since September 2016 (March 2017: $12.2 \pm 5.0 \%$ ). As a result, Porites spp., Pocillopora spp. and other massive/sub-massive taxa have replaced 

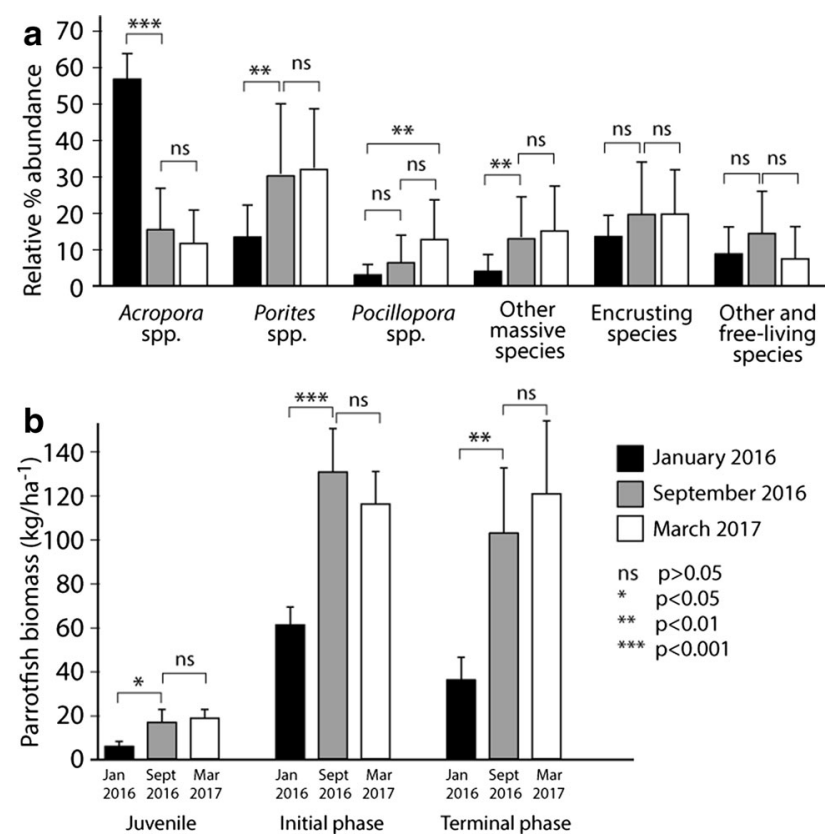

Fig. 3 Plots showing changes in a relative abundance (\%) of dominant coral taxa/groups, and $\mathbf{b}$ biomass $\left(\mathrm{kg} \mathrm{ha}^{-1}\right)$ of parrotfish (grouped by life phase) between Jan 2016, Sept 2016 and March 2017. See Fig. 2 for sites codes

Acropora spp. as the dominant coral taxa (Fig. 3a). At the same time, increases in parrotfish biomass $\left(\mathrm{kg} \mathrm{ha}^{-1}\right)$ occurred at all sites immediate post-bleaching, and measured biomass remained high in March 2017 (Fig. 3b). These increases were significant across all life phases (Fig. 3b). The causes of these increases are unclear, but may relate to increased exploitation of new turf covered substrates on the upper reef slopes by fish that normally inhabit either reef flat or deeper reef slope habitats.

Favourable future ecological trajectories, i.e. recovery of communities dominated by Acropora spp., now depends on coral recruitment and survivorship. However, data collected in March 2017 show that average juvenile coral densities across sites ranged from only $2.7 \pm 4.6$ to $5.8 \pm 12.3$ individuals $\mathrm{m}^{-2}$ (Fig. 4a). When viewed in the context of densities reported after similar time intervals post-1998 bleaching in this region, these densities are very low. For example, McClanahan (2000) reported average juvenile densities of 29 individuals $\mathrm{m}^{-2} 1 \mathrm{yr}$ after the 1998 event, although these juvenile assemblages were dominated by previously subordinate genera (mainly Pavona sp., and Coscinarea sp.) whilst the abundance of juvenile Acropora, Montipora and Pocillopora were low. Similarly, Edwards et al. (2001) reported juvenile densities of $\sim 23$ individuals $\mathrm{m}^{-2}$ on shallow Maldivian reefs some 9 months post1998. Our data indicate that whilst juvenile densities are currently very low on these reefs, previously dominant species of Acropora, Pocillopora and Porites dominate at all sites (Fig. 4b). However, these populations exhibit rather different size class structures. Juvenile Acropora are mainly in the 11-20 mm size class group (Fig. 4c). In the Maldives, Acropora usually spawn in March/April and these juveniles generally grow $10-15 \mathrm{~mm}$ in their first year (Edwards et al. 2001). It thus seems reasonable to assume that most small juvenile Acropora must have settled during 2016 (presumably soon after bleaching), whilst larger juveniles must have survived the bleaching event. Given the larger size structure of Porites and Pocillopora (Fig. 4c), it seems likely that these juveniles also survived the bleaching, providing some hope for future recovery. However, the evident lack of preference to settle on the abundant dead branched framework suggests that the overall ecology and structure of these reefs may undergo further phases of degradation before reorganisation and recovery can begin. Indeed, the paucity of recruits is of further concern given that data collected 9-12 months post-1998 by Bianchi et al. (2006) showed that whilst juvenile densities were initially high these declined rapidly over the next few years before complete recovery ensued.

The data presented here thus collectively suggest that after the initial coral mortality, rates of decline have slowed. Conversely, a downward trajectory in rugosity is predicted as the surficial structure of the reefs, currently dominated by in situ dead Acropora spp., continues to degrade to rubble. Based on observations after the 1998 bleaching event, this may be a necessary precursor stage before more effective coral recruitment can proceed (e.g. Lasagna et al. 2010). Our field observations also suggest that much of this dead in situ framework is infested by endolithic sponges and that this, along with the elevated parrotfish biomass we report, is likely to speed this process up (see Carballo et al. 2013). Extrapolation of these findings to the wider Maldives obviously requires caution, but it is pertinent to mention that we observed similar widespread coral mortality on reefs within and around two more northern atolls (Gooidoo and Baa) in March 2017, and that widespread mortality was reported across the region immediately after the 2016 event (IUCN 2016). Recovery obviously now depends on successful recruitment. Whilst the dominance of Acropora spp. in the current juvenile population structure is encouraging, the dominant factor may be the low overall densities. The turf and filamentous algae-dominated nature of the standing dead coral structures is unlikely to aid recruitment, and the structures will, in any case, degrade to rubble. Collectively, these observations raise concerns over the potential for community recovery at these sites, a concern exacerbated by the recent retrospective ecological analyses of post-1998 bleaching trends in the Seychelles, where coral cover was also decimated. At these sites, early post-bleaching juvenile coral densities of $>6.2$ individuals $\mathrm{m}^{-2}$ (i.e. higher than we 

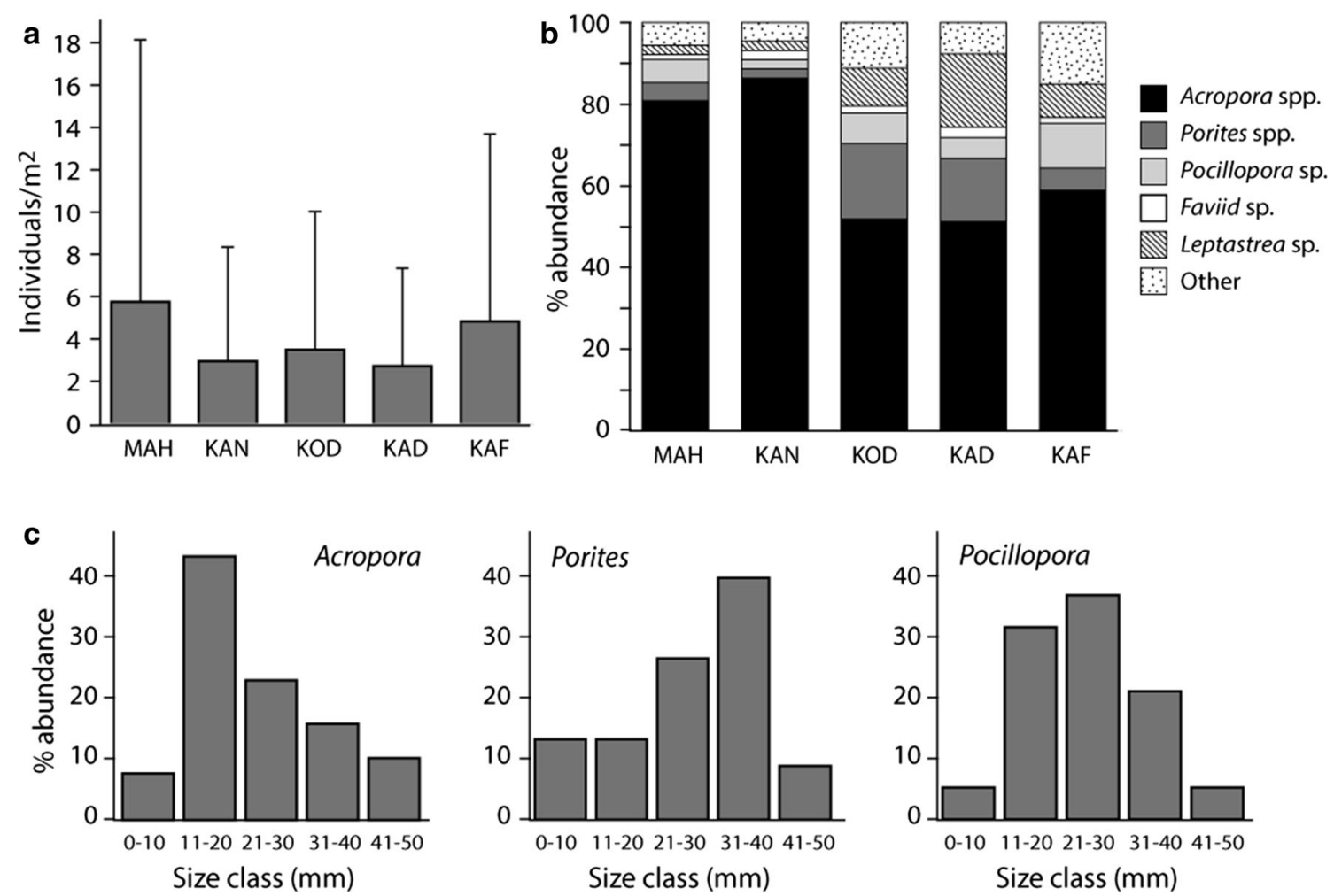

Fig. 4 Plots showing a mean juvenile coral densities $( \pm$ SD) in March 2017; b relative abundance (\%) of juvenile corals in March 2017 (site codes as in Fig. 2); and c size class distribution of juvenile corals for the three previously dominant coral taxa

report) were necessary for those reefs to recover to coraldominated states rather than shifting to macroalgae-dominated states (Graham et al. 2015). Successful juvenile recruitment in the next few years, as well as the frequency and intensity of future bleaching events, will thus be critical determinants of both rates and trajectories of reef community change at these sites, but it is reasonable to assume timescales of recovery will be at least the same time (10-12 yr) as after the 1998 event.

Acknowledgements This work was funded through a Leverhulme Trust Fellowship (RF-2015-152) to C.T.P. We thank the LaMer Small Island Research Centre, Faaresmathooda for assistance with fieldwork.

Open Access This article is distributed under the terms of the Creative Commons Attribution 4.0 International License (http://crea tivecommons.org/licenses/by/4.0/), which permits unrestricted use, distribution, and reproduction in any medium, provided you give appropriate credit to the original author(s) and the source, provide a link to the Creative Commons license, and indicate if changes were made.

\section{References}

Baker AC, Glynn PW, Riegl B (2008) Climate change and coral reef bleaching: an ecological assessment of long-term impacts, recovery trends and future outlook. Estuar Coast Shelf Sci $80: 435-471$
Barott KL, Rodriguez-Mueller B, Youle M, Marhaver KL, Vermeij MJA, Smith JE, Rohwer FL (2012) Microbial to reef scale interactions between the reef-building coral Montastraea annularis and benthic algae. Proc $\mathrm{R}$ Soc Lond $\mathrm{B}$ Biol Sci 279:1655-1664

Bianchi CN, Morri C, Pichon M, Benzoni F, Colantoni P, Baldelli G, Massimo S (2006) Dynamics and pattern of coral recolonization following the 1998 bleaching event in the reefs of the Maldives. Proc 10th Int Coral Reef Symp 1:30-37

Carballo JL, Bautista E, Nava H, Cruz-Barraza JA, Chavez JA (2013) Boring sponges, an increasing threat for coral reefs affected by bleaching events. Ecol Evol 3:872-886

Doropoulos C, Ward S, Roff G, González-Rivero M, Mumby PJ (2015) Linking demographic processes of juvenile corals to benthic recovery trajectories in two common reef habitats. PLoS One 10:e 0128535

Edwards AJ, Clark S, Zahira H, Rajasuriya A, Naseer A, Rubens J (2001) Coral bleaching and mortality on artificial and natural reefs in Maldives in 1998, sea surface temperature anomalies and initial recovery. Mar Pollut Bull 42:7-15

Graham NAJ, Jennings S, MacNeil MA, Mouillot D, Wilson SK (2015) Predicting climate-driven regime shifts versus rebound potential in coral reefs. Nature 518:94-97

Hughes TP et al. (2017) Global warming and recurrent mass bleaching of corals. Nature 17:373-377

IUCN (2016) Maldives coral reefs under stress from climate change. International Union for Conservation of Nature, Gland, Switzerland. http://www.iucn.org/news/maldives-coral-reefsunder-stress-climate-change-research-survey-reveals-over-60corals

Lasagna R, Albertelli G, Colantoni P, Morri C, Bianchi CN (2010) Ecological stages of Maldivian reefs after the coral mass mortality of 1998. Facies 56:1-11 
McClanahan TR (2000) Bleaching damage and recovery potential of Maldivian coral reefs. Mar Pollut Bull 40:587-597

NOAA (2016) Coral Reef Watch, updated daily. NOAA Coral Reef Watch Daily Global 5-km Satellite Virtual Station Time Series Data for the Maldives, 1/1/16 to 1/4/17. College Park, Maryland, USA: http://coralreefwatch.noaa.gov/vs/index.php

Perry CT, Morgan KM (2017) Bleaching drives collapse in reef carbonate budgets and reef growth potential on southern Maldives reefs. Sci Rep 7:40581

Pisapia C, Burn D, Yoosuf R, Najeeb A, Anderson KD, Pratchett MS (2016) Coral recovery in the central Maldives archipelago since the last major mass-bleaching, in 1998. Sci Rep 6:34720
Pratchett MS, McCowan D, Maynard JA, Heron SF (2013) Changes in bleaching susceptibility among corals subject to ocean warming and recurrent bleaching in Moorea, French Polynesia. PLoS One 8:e70443

Sheppard CRC, Harris A, Sheppard ALS (2008) Archipelago-wide coral recovery patterns since 1998 in the Chagos Archipelago, central Indian Ocean. Mar Ecol Prog Ser 362:109-117

van Hooidonk R, Maynard J, Tamelander J, Gove J, Ahmadia G, Raymundo L, Williams G, Heron SF, Planes S (2016) Localscale projections of coral reef futures and implications of the Paris Agreement. Sci Rep 6:39666 